\title{
RECEPTORES DE PROGESTERONA Y GRADO HISTOLÓGICO DEL CÁNCER DUCTAL DE GLÁNDULA MAMARIA
}

Juan Carlos Bonilla MD*,Ginna Rocío Pineda Combaríza**, Carlos Fernando Barrios Torres**

\section{Resumen}

El presente estudio buscó determinar la frecuencia porcentual que existe en la expresión para receptores hormonales de progestágenos y estrógenos según el grado de diferenciación histológica del carcinoma de glándula mamaria (GM). Se revisaron 56 pacientes con cáncer de GM en el Hospital de San José en el período comprendido entre enero 1 de 2004 a enero 31 de 2006, a quienes en la biopsia se les practicó análisis de inmunohistoquímica para receptores de estrógenos y progestágenos. La información se recolectó en una base de datos y se analizó en el programa estadístico EPI INFO 6.0. De los 56 casos estudiados 16 fueron diagnosticados como grado 1 (28.6\%), 26 grado 2 (46.4\%) y 14 grado 3 (25\%). De la totalidad de casos marcados para receptores de estrógenos 40 expresaron positividad y para progestágenos 36. Este estudio demostró que la frecuencia del porcentaje de positividad para receptores de estrógenos y progestágenos está relacionada con el grado de diferenciación histológica del tumor.

Palabras clave: receptores hormonales, receptores de progesterona, receptores de estrógeno, cáncer mamario.

Abreviaturas: GM, glándula mamaria.

\section{Introducción}

El cáncer de GM en mujeres es una de las primeras causas de muerte en el mundo ${ }^{1}$ y en Colombia es la segunda después del de cuello uterino. ${ }^{2}$ Con el fin de prevenir estas muertes se han realizado múltiples estudios y en algunos de estos se cita la relación entre los niveles de hormonas tipo estrógenos y progestágenos y la presencia de carcinoma mamario. Se dice que la expresión de receptores hormonales en el tejido tumoral junto con otras variables macroscópicas y microscópicas han mostrado ser indicadores de pronóstico, siendo también útiles en la decisión

\footnotetext{
Fecha recibido: 26 de octubre de 2006 -Fecha aceptado: 27 de noviembre de 2006

* Médico patólogo del Hospital de San José y Profesor Asistente de la Fundación Universitaria de Ciencias de la Salud.

** Estudiantes de Citohistotecnología de la Fundación Universitaria de Ciencias de la Salud.
}

de instaurar a la paciente la terapia antihormonal., A partir de algunas investigaciones se ha propuesto un cierto factor protector de los progestágenos y estrógenos en neoplasias glándula mamaria. ${ }^{5,6,7} \mathrm{Se}$ considera que la expresión de receptores para progestágenos se puede relacionar con el grado histológico de los tumores y así mismo con el comportamiento biológico y el pronóstico. Expuesta la situación actual del tema, se propone establecer una relación entre el grado histológico de los carcinomas de GM y su expresión de receptores para progestágenos y estrógenos, como posible predictor pronóstico y determinar el comportamiento de las hormonas y su porcentaje de receptores. 


\section{Métodos}

Se realizó un estudio retrospectivo, descriptivo; se aplicó en un tamaño de muestra de 56 casos presentes en las bases de datos del servicio de patología del Hospital de San José, de mujeres que tuvieron un diagnóstico de cáncer de GM y a las cuales se les realizó biopsia para estudio con coloraciones de rutina y pruebas de inmunohistoquímica para receptores hormonales de estrógenos y progestágenos. Se analizaron las historias clínicas y se complementó la información mediante la lectura por el patólogo de las láminas existentes en el archivo; estos datos se registraron en una base de datos creada en Microsoft Excel 2002, los cuales se analizaron en el programa estadístico EPI INFO 6.0.

\section{Resultados}

El presente estudio tuvo como finalidad graduar el porcentaje de expresión de receptores hormonales para progestágenos y estrógenos de acuerdo con el grado de diferenciación histológico del cáncer de GM. De los $56(100 \%)$ casos analizados 16 (28.6\%) fueron diagnosticados como grado 1 (bien diferenciado), 26 (46.4\%) grado 2 (moderadamente diferenciado) y $14(25 \%)$ grado 3 (pobremente diferenciado) (Tabla 1).

Tabla I. Frecuencia de cáncer de mama según el grado histológico

\begin{tabular}{|c|c|c|c|}
\hline \multicolumn{4}{|c|}{ Frecuencia } \\
\hline $\begin{array}{c}\text { Grado } \\
\text { Histológico }\end{array}$ & Frecuencia & Porcentaje & $\begin{array}{c}\text { Porcentaje } \\
\text { acumulado }\end{array}$ \\
\hline 1 & 16 & $28,6 \%$ & $28,6 \%$ \\
\hline 2 & 26 & $46,4 \%$ & $75,0 \%$ \\
\hline 3 & 14 & $25,0 \%$ & $100,0 \%$ \\
\hline Total & 56 & $100,0 \%$ & $100,0 \%$ \\
\hline
\end{tabular}

En cuanto a las pruebas de inmunohistoquímica para receptores de estrógenos en los 16 casos, grado histológico 1, tres fueron negativos, dos expresaron positividad entre 1 y $50 \%$ y once marcaron positivi- dad en un porcentaje entre $51 \%$ y $100 \%$. Para los 26 casos grado histológico ${ }^{2}$, seis fueron negativos, seis marcaron un porcentaje entre $1 \%$ y $50 \%$ y catorce entre 51 y $100 \%$. De los catorce casos grado histológico 3 , siete fueron negativos, uno marcó entre 1 y $50 \%$ y seis entre 51 y $100 \%$. (Tabla 2).

Tabla 2. Frecuencia de receptores de estrógenos según grado histológico

\begin{tabular}{|c|c|c|c|c|}
\hline \multicolumn{5}{|c|}{ Receptores de Estrógenos } \\
\hline $\begin{array}{c}\text { Gradógico } \\
\text { Histológico }\end{array}$ & $0 \%$ & $1-50 \%$ & $51-100 \%$ & TOTAL \\
\hline 1 & 3 & 2 & 11 & 16 \\
\hline 2 & 6 & 6 & 14 & 26 \\
\hline 3 & 7 & 1 & 6 & 14 \\
\hline TOTAL & 16 & 9 & 31 & 56 \\
\hline
\end{tabular}

En relación con las pruebas de inmunohistoquímica para receptores de progestágenos, de los 16 casos grado histológico 1, cuatro fueron negativos, tres marcaron entre 1 y $50 \%$ y 9 entre 51 y $100 \%$. Para los 26 grado histológico 2 , nueve fueron negativos, ocho marcaron entre 1 y $50 \%$ y nueve entre 51 y $100 \%$. De los catorce casos grado histológico 3, siete fueron negativos, dos marcaron entre 1 y $50 \%$ y cinco entre 51 y $100 \%$. (Tabla 3).

Tabla 3. Frecuencia de receptores de progesterona según el grado histológico

\begin{tabular}{|c|c|c|c|c|}
\hline \multicolumn{5}{|c|}{ Receptores de Progestágenos } \\
\hline $\begin{array}{c}\text { Grado } \\
\text { Histológico }\end{array}$ & $0 \%$ & $1-50 \%$ & $51-100 \%$ & TOTAL \\
\hline 1 & 4 & 3 & 9 & 16 \\
\hline 2 & 9 & 8 & 9 & 26 \\
\hline 3 & 7 & 2 & 5 & 14 \\
\hline TOTAL & 20 & 13 & 23 & 56 \\
\hline
\end{tabular}

En cuanto a la edad, para el grado histológico 1 se obtuvo un mínimo de 29 años, la media de 49,5 y la máxima de 72 años. En el grado histológico 2 la mínima fue de 28 años, la media de 51 y la máxima 
de 79 años. En el grado histológico 3 la mínima fue de 38 años, la media de 59 y la máxima de 73 años (Tabla 4). Es importante mencionar que de la totalidad de las pacientes estudiadas, dos no tuvieron un registro relacionado con la edad.

Tabla 4. Tabla de edades según el grado histológico

\begin{tabular}{|c|c|c|c|}
\hline \multicolumn{5}{|c|}{ Edades } \\
\hline $\begin{array}{c}\text { Edad } \\
\text { mínima }\end{array}$ & $\begin{array}{c}\text { Edad } \\
\text { media }\end{array}$ & $\begin{array}{c}\text { Edad } \\
\text { máxima }\end{array}$ & $\begin{array}{c}\text { Desviación } \\
\text { Estándar }\end{array}$ \\
\hline 29 & 49 & 72 & 13,4943 \\
\hline 28 & 51 & 79 & 12,2578 \\
\hline 38 & 59 & 73 & 10,4179 \\
\hline
\end{tabular}

\section{Discusión}

Está demostrado que los tumores mejor diferenciados expresan una marcación positiva que varía entre 1 y $100 \%$ y que la mayoria de estos tumores estan entre el grado I y II de diferenciación histologica según la clasificación de Bloom y Richardson. Sin embargo, con nuestro estudio la mayoría de los tumores fueron grado histológico II y III (71\%), probablemente relacionada con el grado de desarrollo de nuestro pais, ya que en paises avanzados la mayoría de tumores malignos de GM se detectan en estadíos más tempranos (grado I).

Las cifras del DANE en Colombia revelan que en el 2002 la cifra de muerte en mujeres causada por cáncer de seno fue de 1.716, que lo ubican como la segunda causa de muerte en la población femenina después del de cuello uterino; por lo tanto, es preocupante ver como a pesar de los múltiples estudios que se hacen en relación con este cáncer, las cifras de mortalidad aumentan cada año. Es de vital importancia continuar los estudios acerca del impacto de las pruebas diagnósticas, tanto nuevas como las ya existentes y estandarizadas, y el comportamiento del cáncer, con el fin de mejorar la calidad de vida de las pacientes y apoyar al clínico para instaurar el tratamiento apropiado.

Por otro lado, cabe resaltar que 40 del total de casos estudiados (71.4\%) expresaron p ositividad para receptores de estrógeno y de estos 25 $(44.6 \%)$ se encontraron entre los grados de diferenciación histológica I y II, lo cual concuerda con la literatura universal.

En cuanto a la progesterona, se demostró que su comportamiento fue muy similar al relacionado con los estrógenos, ya que $36(64.2 \%)$ casos marcaron positividad entre 1 y $100 \%$. Sin embargo, estos hallazgos no son concluyentes y plantean la misma duda sobre el papel mitogénico o antimitogénico de esta hormona en la génesis del carcinoma de GM, pues en la literatura algunos autores plantean que los progestágenos actúan como agentes proliferativos y en consecuencia se aumenta el número de mitosis y el riesgo de nuevas mutaciones, en especial en los genes promotores del cáncer de GM. Algunos plantean que pueden actuar como agentes antiproliferativos disminuyendo así la tasa de proliferación celular.

Se recomienda realizar estudios más especializados acerca del comportamiento hormonal en relación con el cáncer de mama, sobre todo de la progesterona, con el fin de disipar las dudas aun existentes.

\section{Conclusiones}

-La mayoría de tumores malignos de GM fueron grado histológico II (moderadamente diferenciado).

-Un alto número de los tumores marcaron estrógenos positivos y de estos la mayor parte fueron los mejores diferenciados (I y II).

- Los receptores de progesterona se comportan en estaserie de una manera similar a los estrógenos, de tal forma que el papel de la progesterona en el desarrollo de cáncer mamario continua siendo una incógnita que amerita más observación en el futuro. 


\section{Referencias}

1. Torrades S. El origen genético del cáncer de mama. Offarm.2003; 22 (6): 108-12.

2. Jaramillo R, Bravo L, Carrascal E, Tamayo O. Expresión de receptores hormonales frente a indicadores pronósticos en carcinoma de mama. Colomb Med. 2002; 33: 156-61.

3. Pérez Machín M, Arbolaéz Estrada M, La Rosa Reyes JL, Cid Rios M. Evaluación pronostica y terapéutica de la utilización del método cualitativo en la determinación de la hormonodependencia. VII congreso virtual hispanoamericano de anatomía patológica y I congreso de preparaciones virtuales por Internet; 2005 Oct 1-31; Ciudad Real, España; 2005. p. 1-3.
4. Gabino Sánchez E, Miranda H, Mares J, Medina E, Grifaldo B, González J, et al. Factores pronósticos en cáncer de mama. Gamo. Abr-Jun 2004; 3 (2): 28-32.

5. Yongxian M, Pragati K, Laudentte P, Saijun F, Zhang Y. The breast cancer susceptibility gene BRCA 1 regulates progesterone receptor signaling in mammary epithelial cell. Mol Endocrinol. 2006; 20: 14-34.

6. Santen RJ. Risk of breast cancer with progestins: critical assessment of current data. Steroids. 2003; 68 (10-13): 953-64.

7. Pujol P, Daures JP, Thezenas S, Guilleux F, Rouanet P, Grenier J. Changing estrogen and progesterone receptor patterns in breast carcinoma during the menstrual cycle and menopause. Cáncer. 1998 Aug 15; 83 (4): 698-705.
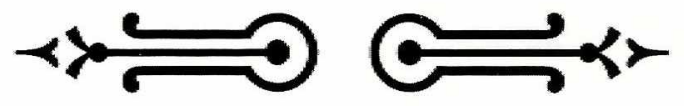

\section{FUNDACIÓN UNIVERSITARIA DE CIENCIAS DE LA SALUD HOSPITAL DE SAN JOSE}

Personería Jurídica No. 10917 Diciembre 1 de 1976 Resolución Ministerio de Educación Nacional No. 0125

Facultad de Instrumentación Quirúrgica

Código ICFES 270246100281100111100

Título otorgado Instrumentador Quirúrgico

Duración 8 semestres

No. créditos a cursar: 165

Modalidad: presencial

1

\begin{tabular}{|c|c|c|c|c|c|c|c|}
\hline I SEMESTRE & II SEMESTRE & III SEMESTRE & IV SEMESTRE & V SEMESTRE & VI SEMESTRE & VII SEMESTRE & VIII SEMESTRE \\
\hline $\begin{array}{l}\text { - Biología } \\
\text { - Morfofisiología } \\
\text { I } \\
\text { - Física } \\
\text { - Introducción a } \\
\text { la instrument- } \\
\text { ación } \\
\text { - Comunicación } \\
\text { oral y escrita } \\
\text { - Informática } \\
\text { - Bioquímica }\end{array}$ & $\begin{array}{l}\text { - Microbiología } \\
\text { - Morfofisiología } \\
\text { II } \\
\text { - Esterilización } \\
\text { - Técnicas } \\
\text { quirúrgicas I } \\
\text { - Técnicas de } \\
\text { instrument- } \\
\text { ación I } \\
\text { - Sociología }\end{array}$ & $\begin{array}{l}\text { - Patología II } \\
\text { - Cuidados básicos } \\
\text { en salud } \\
\text { - Anestesia } \\
\text { - Técnicas } \\
\text { quirúrgicas II } \\
\text { - Técnicas de } \\
\text { instrumentacion II } \\
\text { - Inglés II } \\
\text { - Psicología }\end{array}$ & $\begin{array}{l}\text { - Patología II } \\
\text { - Técnicas } \\
\text { quirúrgicas III } \\
\text { - Técnicas de } \\
\text { instrumentación } \\
\text { III } \\
\text { - Inglés III } \\
\text { - Constitucion } \\
\text { política } \\
\text { y derecho en } \\
\text { salud } \\
\text { - Ética general } \\
\text { - Administración } \\
\text { general }\end{array}$ & $\begin{array}{l}\text { - Bioética } \\
\text { - Administración } \\
\text { hospitalaria } \\
\text { - Investigación } \\
\text { - Inglés IV } \\
\text { - Salud ocupacional } \\
\text { - Técnicas de } \\
\text { instrumentación IV } \\
\text { - Técnicas } \\
\text { quirúrgicas IV }\end{array}$ & $\begin{array}{l}\text { - Práctica I } \\
\text { - Investigación } \\
\text { - Mercadeo } \\
\text { - Trabajo de } \\
\text { grado I } \\
\text { a }\end{array}$ & $\begin{array}{l}\text { - Práctica II } \\
\text { - Trabajo de } \\
\text { grado II }\end{array}$ & - Práctica III \\
\hline
\end{tabular}

- El estudiante debe cursar durante la duración del programa diez créditos de asignaturas electivas.

Oficina de admisiones: Carrera 19 No. 8 A-32 Edificio Docente, 1er. pisc PBX. 5998977 • 5998842 TEL. 2019867 •TELEFAX 2018938 E-mail: instrumentacion@fucsalud.edu.co hppt: www.fucsalud.edu.co 